\title{
Erratum to: Biodegradation of Aldrin and Dieldrin by the White- Rot Fungus Pleurotus ostreatus
}

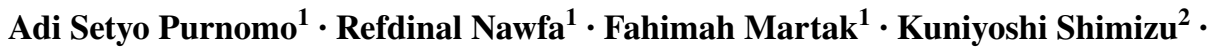 \\ Ichiro Kamei $^{3}$
}

Published online: 10 April 2017

(C) Springer Science+Business Media New York 2017

\section{Erratum to: Curr Microbiol (2017) 74:320-324 \\ DOI 10.1007/s00284-016-1184-8}

The original version of this article unfortunately contained a mistake. In Fig. 3 the structure of 9-hydroxyaldrin was incorrect. The correct Fig. 3 is given below.

Fig. 3 Proposed pathways for metabolism of aldrin by Pleurotus ostreatus

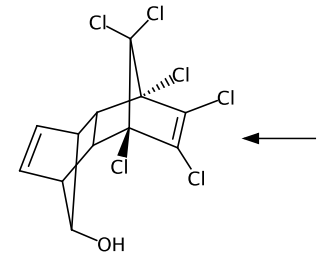

9-hydroxyaldrin<smiles>ClC1=C(Cl)[C@]2(Cl)[C@H]3C=C[C@H](C3)[C@@]1(Cl)C2(Cl)Cl</smiles>

Aldrin<smiles></smiles>

Dieldrin

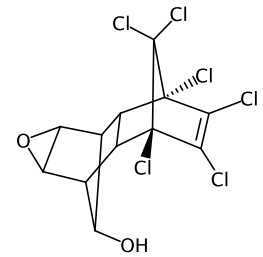

9-hydroxydieldrin

The online version of the original article can be found under doi:10.1007/s00284-016-1184-8.

Adi Setyo Purnomo

adi_setyo@chem.its.ac.id; adi.spurnomo@yahoo.com

1 Department of Chemistry, Faculty of Mathematics and Natural Sciences, Institut Teknologi Sepuluh Nopember

(ITS), Kampus ITS Sukolilo, Surabaya 60111, Indonesia

2 Department of Agro-environmental Sciences, Faculty of Agriculture, Kyushu University, 6-10-1 Hakozaki, Higashi-ku, Fukuoka 812-8581, Japan

3 Department of Forest and Environmental Sciences, Faculty of Agriculture, University of Miyazaki, 1-1 Gakuen-kibanadai-nishi, Miyazaki 889-2192, Japan 